\title{
Regulation of Drug Reward by cAMP Response Element- Binding Protein: Evidence for Two Functionally Distinct Subregions of the Ventral Tegmental Area
}

\author{
Valerie G. Olson, ${ }^{1}$ Cyrus P. Zabetian,,${ }^{1,2}$ Carlos A. Bolanos, ${ }^{1}$ Scott Edwards, ${ }^{1}$ Michel Barrot, ${ }^{1}$ Amelia J. Eisch, ${ }^{1}$ \\ Thomas Hughes, ${ }^{3}$ David W. Self, ${ }^{1}$ Rachael L. Neve, ${ }^{4}$ and Eric J. Nestler ${ }^{1}$ \\ ${ }^{1}$ Department of Psychiatry and Center for Basic Neuroscience, The University of Texas Southwestern Medical Center, Dallas, Texas 75390-9070, \\ ${ }^{2}$ Department of Psychiatry, Veterans Affairs Connecticut Healthcare System, West Haven, Connecticut 06516, ${ }^{3}$ Department of Ophthalmology, Yale \\ University School of Medicine, New Haven, Connecticut 06510, and ${ }^{4}$ Department of Psychiatry, Harvard Medical School and McLean Hospital, Belmont, \\ Massachusetts 02478
}

The transcription factor cAMP response element binding protein (CREB) is implicated in the actions of drugs of abuse in several brain areas, but little information is available about a role for CREB in the ventral tegmental area (VTA), one of the key reward regions of the brain. Here, we demonstrate that chronic exposure to drugs of abuse induces CREB activity throughout the VTA. Using viral-mediated gene transfer, we expressed green fluorescent protein (GFP)-tagged CREB or mCREB (a dominant-negative form of CREB) in the VTA and, using a conditioned place-preference paradigm, found that CREB activation within the rostral versus caudal subregions of the VTA produces opposite effects on drug reward. We identified VTA subregion-specific differences in the proportion of dopaminergic and GABAergic neurons and in the dopaminergic projections to the nucleus accumbens, another brain region implicated in drug reward, and suggest that this may contribute to behavioral differences in this study. We also measured expression levels of tyrosine hydroxylase and the AMPA glutamate receptor subunit GluR1, both of which are known to contribute to drug reward in the VTA, and found that both of these genes are upregulated following the expression of CREB-GFP and downregulated following expression of mCREB-GFP, raising the possibility that CREB may exert its effects on drug reward, in part, via regulation of these genes. These results suggest a novel role for CREB in mediating drug-induced plasticity in the VTA and establish two functionally distinct subregions of the VTA in which CREB differentially regulates drug reward.

Key words: cocaine; reward; ventral tegmental area; CREB; mesocortical; mesolimbic; morphine

\section{Introduction}

Repeated exposure to drugs of abuse causes complex molecular adaptations in discrete brain regions, including the reward circuitry of the brain (Wise, 1996; Koob and Le Moal, 2001; Nestler, 2001). An example of this plasticity is activation of the transcrip-

Received April 1, 2004; revised April 15, 2005; accepted April 17, 2005.

This work was supported by grants from the National Institute on Drug Abuse and the National Institute of Mental Health.

Correspondence should be addressed to Eric J. Nestler, Department of Psychiatry and Center for Basic Neuroscience, The University of Texas Southwestern Medical Center, 5323 Harry Hines Boulevard, Dallas, TX 75390-9070. E-mail: eric.nestler@utsouthwestern.edu.

M. Barrot's present address: Neurophysiologie Cellulaire et Integree, Unité Mixte de Recherche 7519 Centre National de la Recherche Scientifique/Université Louis Pasteur, 21 rue Rene Descartes, 67084 Strasbourg Cedex, France.

C. A. Bolanos' present address: Department of Psychology, Florida State University, Tallahassee, FL 32306-1270. T. Hughes' present address: Department of Cell Biology and Neuroscience, Montana State University at Bozeman, 513 Leon Johnson, Bozeman, MT 59717.

V. G. Olson's present address: Department of Biochemistry, Howard Hughes Medical Institute, 1959 Pacific Avenue, Seattle, WA 98195.

C. P. Zabetian's present address: Department of Neurology, University of Washington School of Medicine and Geriatric Research Education and Clinical Center, Veterans Affairs Puget Sound Health Care System, Seattle, WA 98108.

DOI:10.1523/JNEUROSCI.0345-05.2005

Copyright $\odot 2005$ Society for Neuroscience $\quad 0270-6474 / 05 / 255553-10 \$ 15.00 / 0$ tion factor cAMP response element (CRE)-binding protein (CREB) in several regions following chronic morphine, cocaine, or amphetamine exposure (Guitart et al., 1992; Konradi et al., 1994; Lane-Ladd et al., 1997; Barrot et al., 2002; Shaw-Lutchman et al., 2002, 2003; Walters et al., 2003). CREB regulates the expression of genes by interacting with CREs in their regulatory regions. Several signal transduction pathways activate CREB, suggesting that this transcription factor may integrate signaling information from multiple sources and thereby mediate complex forms of neural plasticity (Bailey et al., 1996; Daniel et al., 1998; Shaywitz and Greenberg, 1999; Mayr and Montminy, 2001; Nestler, 2001).

Prominent in brain reward circuitry is the ventral tegmental area (VTA). Drug induction of phospho-CREB in the VTA has been reported recently (Walters et al., 2003), but direct evidence of the functional role of CREB in the VTA is still lacking. Chronic drug exposure alters expression of many proteins in this region, including components of the cAMP, Ras, and phospholipase $\mathrm{C} \gamma /$ $\mathrm{IP}_{3}$ signaling cascades, all of which can activate CREB (Berhow et al., 1996; Lane-Ladd et al., 1997; Wolf et al., 1999). In addition, some studies have reported increased levels of the glutamate receptor subunits GluR1 and NMDA receptor 1 in the VTA after 
chronic morphine, cocaine, or ethanol administration (Ortiz et al., 1995; Fitzgerald et al., 1996) (but see Carlezon and Nestler, 2002; Wolf, 2003). These effects could lead to glutamatergicmediated increases in intracellular $\mathrm{Ca}^{2+}$ and CREB activation (Perkinton et al., 1999; Rajadhyaksha et al., 1999; Riccio and Ginty, 2002). These lines of evidence led us to hypothesize that drug-induced changes in CREB function in the VTA might mediate some biochemical and behavioral adaptations to chronic drug exposure.

Well established, but often overlooked, functional differences in rostral versus caudal VTA were first demonstrated by Ikemoto et al. (1997b, 1998) using intracranial self-administration of GABAergic compounds. They found that $\mathrm{GABA}_{\mathrm{A}}$ antagonists were reinforcing in rostral VTA, whereas $\mathrm{GABA}_{\mathrm{A}}$ agonists were reinforcing in caudal VTA, and speculated that these differences could be related to the differential expression of $\mathrm{GABA}_{\mathrm{A}}$ receptors in GABAergic and dopaminergic neurons in the VTA (McBride et al., 1999). Similar rostral versus caudal VTA differences in glutamatergic regulation of drug reward have been reported previously (Carlezon et al., 2000). Consequently, we focused on differences in the effects of CREB in rostral and caudal VTA and considered a possible role for GABAergic neurons in this phenomenon.

We now report that CREB-mediated transcription is upregulated in the VTA in response to chronic drug exposure, and that this upregulation has different behavioral consequences depending on the subregion of the VTA involved. Careful anatomical analysis confirmed the presence of two distinct subregions of VTA (rostral and caudal) that differ in both neuronal population and projection to the nucleus accumbens (NAc), which could explain why these two subregions differentially regulate reward.

\section{Materials and Methods}

Animals. The CRE-reporter mice used in this study express a transgene containing CRE-consensus sequences in tandem, upstream of a minimal respiratory syncytial virus promoter, and surrounded by insulator elements (generously provided by Jerry Yin, University of Wisconsin, Madison, WI) (Barrot et al., 2002). Male heterozygote transgenic mice were out-crossed to wild-type C57BL/6 mice and were bred and maintained under a $12 \mathrm{~h}$ light/dark cycle with food and water available ad libitum. Genotyping was performed by PCR, and male and female mice (between 8 and 12 weeks of age) heterozygous for the transgenic sequence were used for all experiments. For each experimental animal, a littermate of the same gender and bearing the reporter transgene was used as a control. Adult male Sprague Dawley rats (Charles River, Kingston, NY) were used for all other experiments and also were maintained under a $12 \mathrm{~h}$ light/ dark cycle with food and water available ad libitum. Rats were used for viral and tracer injections and for studies of target genes because of the larger size of their brains and the ability to more easily discriminate between VTA subregions. In contrast, the CRE-LacZ mice provide a unique means of studying regulation of CRE-mediated transcription in the brain in vivo, which is not possible in the rat.

Drug administration to transgenic mice. In experiments examining CREB activation after chronic morphine administration, morphine was administered chronically twice daily by intraperitoneal injection of an escalating dose of morphine sulfate over $5 \mathrm{~d}(10,20,40,80$, and 100 $\mathrm{mg} / \mathrm{kg}$ ) or saline injections of an equal volume (Shaw-Lutchman et al., 2002). To ensure that Cre-LacZ activation was not attributable to the acute effects of morphine, animals were killed with an overdose of pentobarbital $12 \mathrm{~h}$ after the final injection and perfused transcardially with saline followed by $4 \%$ paraformaldehyde in $0.1 \mathrm{~m}$ phosphate buffer. At this time point, levels of CRE activity returned to normal levels in the VTA and other brain regions after a single injection of morphine (100 $\mathrm{mg} / \mathrm{kg}$ ) (Shaw-Lutchman et al., 2002).

Immunohistochemistry and anatomical analysis. Brains were postfixed for $12 \mathrm{~h}$ and then cryoprotected in $20 \%$ glycerol in $0.1 \mathrm{M}$ phosphate buffer for $12 \mathrm{~h}$. Brains were then cut ( $40 \mu \mathrm{m}$ sections) coronally on a freezing microtome and stored in PBS with $0.05 \%$ sodium azide. In experiments using transgenic mice, LacZ expression was detected with a polyclonal antibody to $\beta$-galactosidase ( $\beta$-gal) (1:5000; Biogenesis, Poole, UK), and some sections were double labeled for tyrosine hydroxylase (TH) (1: 1000; Chemicon, Temecula, CA) to determine whether the $\beta$-galpositive neurons were dopaminergic. To directly test the influence of herpes simplex virus (HSV) vectors on CRE-mediated transcription, mice positive for the CRE-LacZ transgene were injected with HSVCREB-green fluorescent protein (GFP), HSV-mCREB-GFP (a dominant-negative form of CREB with a mutation at the serine 133 phosphorylation site that prevents phosphorylation and transactivation and blocks the activity of endogenous CREB) (Carlezon et al., 1998), or HSV-Cre-GFP (a viral vector expressing the bacterial protein Cre recombinase tagged with GFP, which is inactive in the absence of a floxed gene) $3 \mathrm{~d}$ before use. In all cases, antibody labeling was visualized using cyanine 2 (Cy2) and Cy3 fluorophore-labeled secondary antibodies (1:200; Jackson ImmunoResearch, West Grove, PA), and sections were mounted onto slides in DPX (a mixture of distyrene, tricresyl phosphate, and xylene) mounting media (Fluka BioChemika, Ronkonkoma, NY). Several sections from injected mice were taken at five anatomical points throughout the VTA: $-2.92,-3.08,-3.16,-3.28$, and $-3.40 \mathrm{~mm}$ bregma; the first three points were within the territory of the rostral VTA, whereas the latter two points were in the territory of the caudal VTA. Total CRE-LacZ-positive neurons with expression above basal background levels were counted using a technique described previously (Barrot et al., 2002). In experiments quantifying transgenes and cell type in rats, sections were labeled with either an antibody to TH (see above) or to GAD65 and GAD67 (1:10,000; Sigma) and either an antibody to $\beta$-gal (see above) or GFP (1:1000; Upstate Biotechnology, Waltham, MA) depending on the transgene expressed.

Viral vectors. Construction and packaging of viral vectors has been described previously (Neve et al., 1997). Transgenes (LacZ, Cre recombinase-GFP, CREB-GFP, and mCREB-GFP) were inserted into the HSV PrpUC amplicon under the control of an HSV 4/5 immediate early gene promoter, packaged with helper virus $5 \mathrm{dl} 1.2$, purified on a sucrose gradient, pelleted, and resuspended in 10\% sucrose. The average titer of viral stocks was $2.0 \times 10^{7}$ infectious units $/ \mathrm{ml}$. CREB-GFP and mCREBGFP fusion proteins were created by adding a GFP tag to the $\mathrm{N}$ terminus of CREB and mCREB. Previous studies have indicated that tagging the $\mathrm{N}$ terminus of CREB does not interfere with its functional activity (Chao et al., 2002). Functional activity of these constructs was confirmed in cell culture, in which overexpression of CREB-GFP increased while overexpression of mCREB decreased CRE-mediated transcription (data not shown). After intra-VTA injection, maximal expression of all viralencoded transgenes is observed at $24 \mathrm{~h}$ after injection and persists for 3-4 $\mathrm{d}$ after injection and then dissipates and is not detectable by day 7 , as reported previously (Carlezon et al., 1997; Barrot et al., 2002). This time course is independent of the particular transgene expressed.

Surgery. Surgery was performed as described previously (Barrot et al., 2002). Animals were anesthetized and received unilateral injections into the VTA [rats: $2 \mu \mathrm{l}$ of virus stock; anteroposterior (AP), -4.9 to -6.2 mm caudal to bregma; lateral $(\mathrm{L}),+2.1 \mathrm{~mm}$ from the midline; arm set at a $10^{\circ}$ angle toward the midline; dorsoventral (DV), $-7.3 \mathrm{~mm}$ from dura; mice: $0.5 \mu$ l of virus stock; $\mathrm{AP},-2.8 \mathrm{~mm}$ caudal to bregma; $\mathrm{L},+1.0 \mathrm{~mm}$ from midline; arm set at a $7^{\circ}$ angle toward midline; DV,$-4.6 \mathrm{~mm}$ from dura] or the lateral substantia nigra pars compacta (rats only: AP, -5.3 $\mathrm{mm}$ caudal to bregma; $\mathrm{L},+3.1 \mathrm{~mm}$ from midline; arm set at a $10^{\circ}$ angle toward midline; DV,$-6.5 \mathrm{~mm}$ from dura), which served as an anatomical control. For sham surgery, the syringe was lowered $1.0 \mathrm{~mm}$ below the dura, but no injection was made. We used unilateral injections, because we found that bilateral injections in the VTA offer no greater biological effect than unilateral injections, and the latter involve less stress to the animal and less labor on the part of the experimenter (Carlezon et al., 1997; Bolanos et al., 2003).

Behavior. Using a balanced and unbiased paradigm, place conditioning occurred in a three-compartment apparatus as described previously (Kelz et al., 1999). This apparatus consisted of a central small shuttle chamber between two larger conditioning chambers, which differed in 
lighting, walls, and floors. Before surgery, animals were placed into the central compartment and allowed to freely explore the entire apparatus for $30 \mathrm{~min}$. Animals that did not show a baseline preference ( $>18 \mathrm{~min}$ ) or a preference for the central chamber $(>8 \mathrm{~min})$ were admitted into the study; $>80 \%$ of all animals met these criteria.

After surgery, animals were allowed either $1 \mathrm{~d}$ of recovery and subsequently conditioned for $3 \mathrm{~d}$ consecutively or were allowed $2 \mathrm{~d}$ of recovery and conditioned for $3 \mathrm{~d}$ consecutively. No significant difference between the two conditioning protocols was observed. These time points were chosen based on the fact that maximal HSV-transgene expression occurs on days 1-4 after surgery (Barrot et al., 2002). On conditioning days, two pairing sessions were given. On the first trial of each day, animals received a volume of saline equivalent to the volume of drug they would receive and were restricted to one of the conditioning chambers for $1 \mathrm{~h}$. After the first pairing session, animals were returned to their home cages and allowed to rest for a minimum of $3 \mathrm{~h}$. On the second trial of each day, animals received a dose of drug and were restricted to the other conditioning chamber for $1 \mathrm{~h}$. Depending on the group, drugs were given as follows: $1.25 \mathrm{mg} / \mathrm{kg}$ cocaine, i.p., or $0.125,0.25$, and $0.5 \mathrm{mg} / \mathrm{kg}$ morphine, s.c. After the final training day, animals were tested for conditioned place preference (CPP) by placing them in the central chamber and allowing them to freely explore the entire apparatus for $30 \mathrm{~min}$. Drug and saline pairings were given at the same time on each conditioning day, and animals were tested for preference at the same time as the drug pairing on the previous day. After testing (or for light microscopy, $3 \mathrm{~d}$ after intracranial injection), animals were overdosed with pentobarbital or chloral hydrate and perfused with $0.1 \mathrm{M}$ PBS and $4 \%$ paraformaldehyde, and the brains were removed and processed as described above. Animals were then assigned to either a rostral $(-4.9$ to $-5.4 \mathrm{~mm}$ bregma $)$ or caudal ( -5.5 to $-6.2 \mathrm{~mm}$ bregma) group depending on the site of injection. Animals in which the placement of the needle was outside of the VTA were excluded from the study. HSV-CREB-GFP, HSV-mCREB-GFP, and several control groups did not show a baseline preference for either side of the apparatus before training.

Western blot analysis. The VTA was rapidly punch-dissected $3 \mathrm{~d}$ after surgery from rats that received intra-VTA injections of HSV-CREB-GFP or HSV-Cre-GFP exactly as described previously (Carlezon et al., 1997). Rostral and caudal VTA could not be dissociated in this experiment because of the limits of microdissection; it is technically not possible to obtain accurate and replicable VTA punches from these subregions because of their small size, subtle interanimal anatomical differences, and the need for speed to preserve proteins levels. Levels of TH and GluR1 immunoreactivity were then measured by Western blot analysis exactly as described previously (Carlezon et al., 1997; Lane-Ladd et al., 1997). Equal loading and transfer was verified by Amido Black staining. TH and GluR1 levels were normalized to $\beta$-tubulin, which was not affected by the HSV treatments. These experiments were performed over a threefold linear range of immunoreactivity levels.

RNA extraction and cDNA synthesis. Fresh tissue samples from rat VTA, isolated as described above, were homogenized in $1 \mathrm{ml}$ of TRIzol reagent (Invitrogen, San Diego, CA) and extracted following the protocol of the manufacturer. RNA was resuspended in DEPC-treated water, quantified from $\mathrm{A}_{260}$ measurements, and assessed for quality by visual inspection of samples electrophoresed on agarose gels. The RNA was treated with $2 \mathrm{U}$ of DNase using the DNA-free kit (Ambion, Austin, TX) and then heated at $65^{\circ} \mathrm{C}$ for $10 \mathrm{~min}$ to inactivate the enzyme. cDNA synthesis was performed using the Superscript First-Strand Synthesis System for reverse transcription (RT)-PCR (Invitrogen) as follows: $1 \mu \mathrm{g}$ of RNA was preincubated with $1 \mu \mathrm{l}$ of Oligo(dT) $12-18(0.5 \mu \mathrm{g} / \mu \mathrm{l})$ and $1 \mu \mathrm{l}$ of $10 \mathrm{~mm}$ deoxyribonucleoside triphosphates at $65^{\circ} \mathrm{C}$ for $5 \mathrm{~min}$. After chilling on ice for $1 \mathrm{~min}, 4 \mu \mathrm{l}$ of First Strand buffer $(5 \times), 2 \mu$ l of DTT $(0.1$ M), $1 \mu \mathrm{l}$ of RNase-OUT, and $1 \mu \mathrm{l}$ (50 U) of Superscript II reverse transcriptase were added for a final volume of $20 \mu$. The mixture was incubated at $42^{\circ}$ for $50 \mathrm{~min}$ and then $70^{\circ} \mathrm{C}$ for $15 \mathrm{~min}$ to terminate the reaction. Each sample was then incubated at $37^{\circ}$ for $20 \mathrm{~min}$ with $2 \mathrm{U}$ of RNase H.

Real-time RT-PCR and data analysis. PCRs were performed using the LightCycler-FastStart DNA Master SYBR Green I kit (Roche Products, Welwyn Garden City, UK) as follows. A total of $2 \mu$ l of cDNA diluted 1:10 in nuclease-free water was added to $2.5 \mu \mathrm{l}$ of FastStart reaction mix, $2 \mu \mathrm{l}$ of $25 \mathrm{~mm} \mathrm{MgCl}_{2}$ (final $\mathrm{MgCl}_{2}$ concentration, $3 \mathrm{~mm}$ ), and water to a final volume of $25 \mu \mathrm{l}$. Thermocycling and detection of the SYBR green I-labeled, double-stranded PCR products were performed using the Smart Cycler System (Cepheid). Thermocycling parameters were as follows: $95^{\circ} \mathrm{C}$ for $10 \mathrm{~min}$ (DNA polymerase activation) followed by 50 cycles of denaturation at $95^{\circ} \mathrm{C}$ for $10 \mathrm{~s}$, annealing at $58^{\circ} \mathrm{C}$ for $10 \mathrm{~s}$, and extension at $72^{\circ} \mathrm{C}$ for $10 \mathrm{~s}$. Optical detection of the fluorescent signal occurred during the extension phase. Each experiment was performed in duplicate, and the results were averaged for data analysis. The cycle threshold $\left(C_{\mathrm{t}}\right)$ was calculated by software supplied by the manufacturer as the cycle during which the second derivative of the fluorescent signal reached maximum value. Data for all genes of interest were normalized to the expression levels of two housekeeping genes (B-actin, GAPDH) by the following formula: $\Delta C_{\mathrm{t}}=C_{\mathrm{t}}$ (gene of interest) $-C_{\mathrm{t}}$ (GAPDH or B-actin). Adjusted expression levels for the HSV-CREB-GFP and HSVmCREB-GFP groups were then calculated relative to controls (HSVCre-GFP) by the following: $\Delta \Delta C_{\mathrm{t}}=\Delta C_{\mathrm{t}}-\Delta C_{\mathrm{t}}$ (control group). Expression levels relative to controls were then calculated using the following expression: $2^{-\Delta \Delta C \mathrm{t}}$. GFP levels were measured in all of the samples to verify expression in the area of the tissue punch. Animals that had no GFP expression, and therefore no viral expression, were excluded from the experiment.

Retrograde labeling studies. Animals used for retrograde labeling studies were injected with hydrostabilamine (HS; a derivative of fluorogold, a retrograde tracer; Molecular Probes, Eugene OR) into the midrostrocaudal shell region of the NAc. Injections were made stereotaxically with a $5 \mu$ l Hamilton microsyringe. The syringe was lowered into the brain, and after $5 \mathrm{~min}$ of equilibration, $0.1 \mu \mathrm{l}$ of HS was delivered over a $10 \mathrm{~min}$ interval. After the injection, the needle was left in the brain for $18 \mathrm{~min}$ to allow for diffusion of the HS. Animals were then allowed to recover for $5 \mathrm{~d}$. On the fifth day, animals were injected with HSV-LacZ at coordinates throughout the VTA. On the seventh day, animals were overdosed with chloral hydrate and perfused transcardially with a volume of $100 \mathrm{ml}$ of ice-cold $0.1 \mathrm{M} \mathrm{PBS}$, pH 7.4, followed by $500 \mathrm{ml}$ of $0.1 \mathrm{M}$ PBS containing 1.4-2\% gluteraldehyde and $2 \%$ paraformaldehyde, $\mathrm{pH}$ 7.4. After perfusion, brains were stored in the same fixative for $1-3 \mathrm{~h}$, followed by $5-6 \mathrm{~h}$ in $20 \%$ glycerol in $0.1 \mathrm{~m}$ PBS solution. Brains were then cut serially from the rostral lateral hypothalamus to the rostral pole of the pons in 10-14 $\mu \mathrm{m}$ sections on a freezing microtome. The shell of the accumbens was also cut to determine accuracy of injection $(>90 \%)$ and the extent of the spread of tracer at the injection site $(\sim 1 \mathrm{~mm})$. Sections were stored in a $0.1 \mathrm{M}$ PBS solution with $0.05 \%$ sodium azide and at $4{ }^{\circ} \mathrm{C}$ in the dark and labeled for $\beta$-gal, TH, and HS (1:2000; Chemicon) as outlined above. Quantification and localization of immunofluorescence was performed on a fluorescent microscope, and triple labeling was confirmed by confocal microscopy. Only sections with $\geq 30 \beta$-gal-labeled cells were included in the study.

\section{Results}

Chronic morphine exposure increases CRE-mediated transcription in the VTA in a topographically specific manner We mapped the ability of chronic morphine administration to activate CRE-mediated transcription in the VTA using CRE$\mathrm{LacZ}$ transgenic mice. Because the VTA is a heterogeneous collection of cell groups, we characterized $\beta$-gal induction by dividing the VTA into two subregions (rostral and caudal VTA) based on functional differences between these subregions reported previously in the rat (Arnt and Scheel-Kruger, 1979; Ikemoto et al., 1997b, 1998; McBride et al., 1999; Ikemoto and Wise, 2002; Zangen et al., 2002; Bolanos et al., 2003). In both rostral and caudal VTA, there was a significant increase in CRE-LacZ-positive cells after chronic morphine exposure (Fig. $1 A$ ).

Because the VTA is known to be populated by both GABAergic and dopaminergic neurons, we next sought to characterize the neuronal type in which this upregulation occurs by colabeling with an antibody to $\mathrm{TH}$, a marker of dopamine neurons. In ros- 

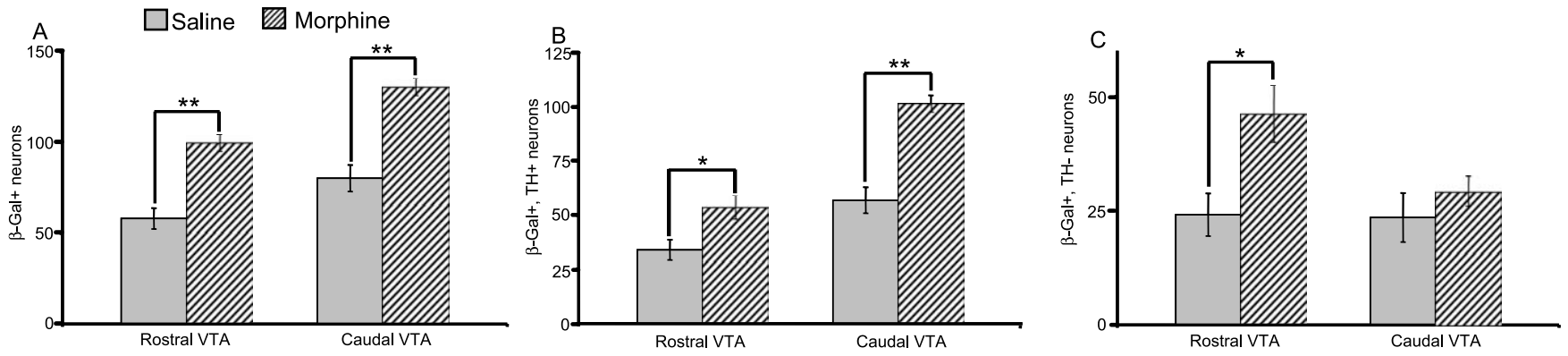

Figure 1. Chronic morphine upregulates CRE-mediated transcription in the VTA. A, CRE-LacZ expression is upregulated by chronic morphine in rostral and caudal VTA relative to saline-treated controls. B, CRE-LacZ expression in dopaminergic neurons (identified by colabeling for TH) is upregulated by chronic morphine in both rostral and caudal VTA. C, CRE-LacZ expression is also upregulated by chronic morphine in nondopaminergic neurons but in rostral VTA only. This rostrocaudal difference was significant $(p<0.05)$ by ANOVA. Data are expressed as cell numbers per section \pm SEM ( $n=8$ animals per group). ${ }^{*} p<0.05 ;{ }^{* *} p<0.01 ; t$ test.

tral and caudal VTA, we observed a significant upregulation of CRE-LacZ in dopaminergic neurons (Fig. 1B). However, in rostral VTA, a significant number of these $\beta$-gal-positive neurons were TH negative (Fig. 1C) (presumably GABAergic), indicating that CREB activation in this region may occur in a more heterogeneous population of neurons than in caudal VTA, a supposition supported by work presented below (see Fig. 6). Thus, these findings suggest that chronic morphine exposure induces CREB activity in partly distinct populations of neurons in rostral versus caudal VTA.

Viral-mediated expression of CREBGFP or mCREB-GFP in the VTA alters conditioned place preference for cocaine in an anatomically distinct manner

Based on our anatomical data that drug induction of CRE activity differs between rostral and caudal VTA and on previously reported data for functional differences between these regions (see the Introduction), we considered the possibility that CREB may differentially regulate the effects of drugs of abuse in the rostral versus caudal VTA. To test this hypothesis, we expressed CREB-GFP or mCREB-GFP in different areas of the rat VTA using HSV vectors. The GFP-tagged fusion proteins made it possible to distinguish transgenic CREB (or mCREB) from endogenous CREB. Cre-GFP (a bacterial protein, Cre recombinase, tagged with GFP) was expressed as a control. We assessed the rewarding effects of cocaine using the place-
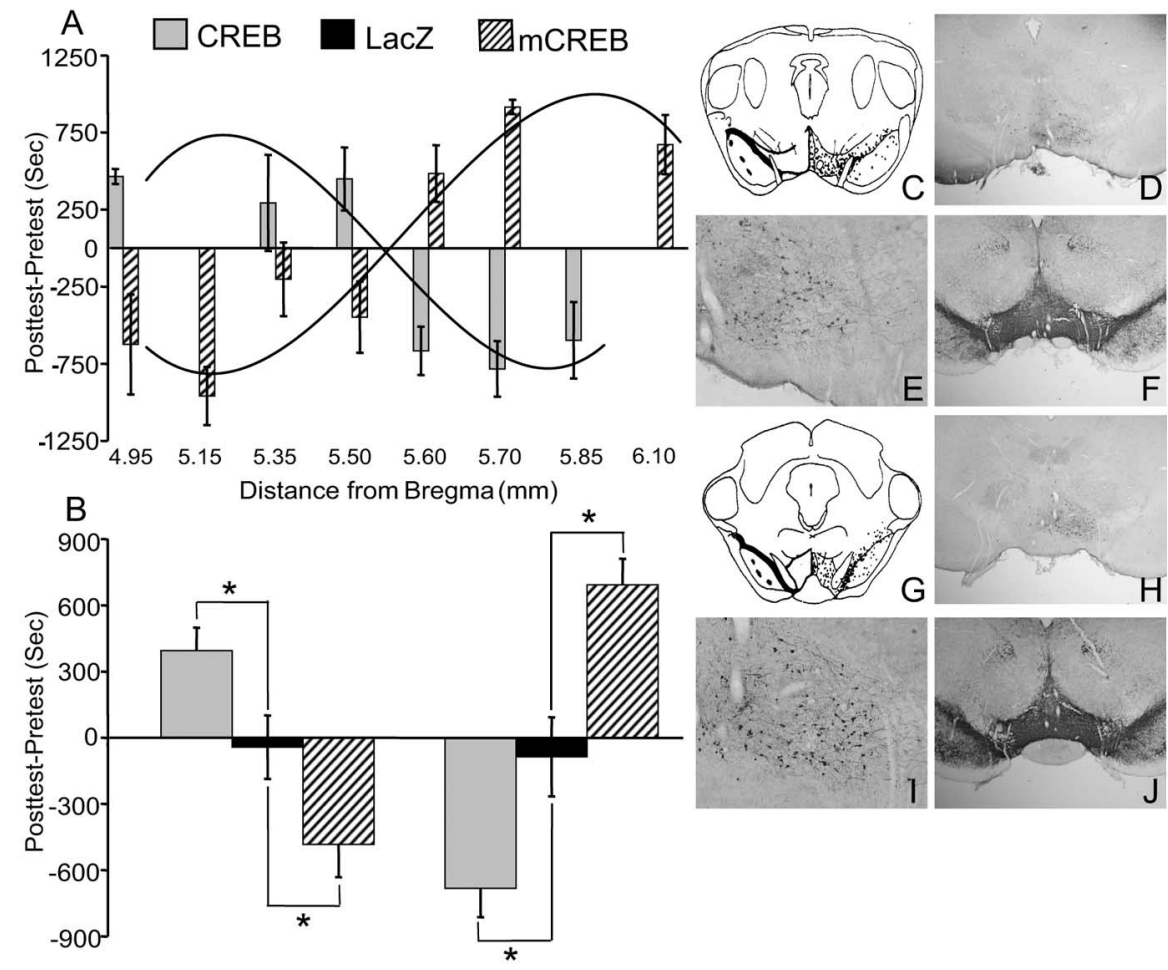

Figure 2. CREB differentially regulates cocaine reward in rostral versus caudal VTA. Animals received injections of HSV-CREBGFP or HSV-mCREB-GFP throughout the rostrocaudal axis of the VTA and then were analyzed for conditioned place preference to a threshold dose of cocaine (1.25 mg/kg, i.p.). Data reported are mean change in time spent on the drug-paired side minus the saline-paired side before and after conditioning ( \pm SEM), which provides a measure of place conditioning. Sham injection controls and HSV-Cre-GFP and HSV-LacZ viral controls were not significantly different and thus were pooled into a single control group. $\boldsymbol{A}$, Place-preference scores (mean \pm SEM) are plotted as a function of the HSV injection site, revealing an inflection point of approximately $-5.5 \mathrm{~mm}$ bregma. $\boldsymbol{B}$, Rostral to this inflection point, HSV-CREB makes a subthreshold dose of cocaine rewarding, whereas HSV-mCREB makes it aversive. Conversely, caudal to this inflection point, HSV-CREB makes the subthreshold dose of cocaine aversive, whereas HSV-mCREB has the opposite effect. ${ }^{*} p<0.05 ; t$ test; $n=6-20$. C, G, Schematic representations of coronal sections through rostral and caudal VTA, respectively. These images are from Paxinos (1995), reprinted with permission. $\boldsymbol{D}, \boldsymbol{E}, \boldsymbol{H}, \boldsymbol{I}$, Representative coronal sections through the VTA of rats injected with HSV-CREB-GFP into the rostral or caudal VTA and immunohistochemically labeled with an antibody to GFP. F, J, Adjacent sections labeled with an antibody to TH. conditioning paradigm, in which animals learn to prefer a drug-paired environment. In an attempt to map different functional subregions of the VTA, we plotted placepreference scores as a function of the placement of viral infection in each rat. The results are shown in Figure 2. From these data, we identified two functionally different subregions in rat VTA. In rostral VTA, which spans the supramammillary area to the rostral pole of the interpeduncular nucleus ( -4.9 to $-5.4 \mathrm{~mm}$ bregma),

expression of CREB-GFP made a threshold dose of cocaine highly rewarding, whereas mCREB-GFP made this dose of cocaine aversive. Conversely, in caudal VTA, which spans the rostral pole of the interpeduncular nucleus to the caudal end of the VTA $(-5.5$ to $-6.2 \mathrm{~mm}$ bregma), CREB-GFP expression made the threshold dose of cocaine aversive, whereas mCREB-GFP made this cocaine dose highly rewarding (Fig. $2 A, B$ ). These two anatomical areas correlate well with previous studies describing two functionally 


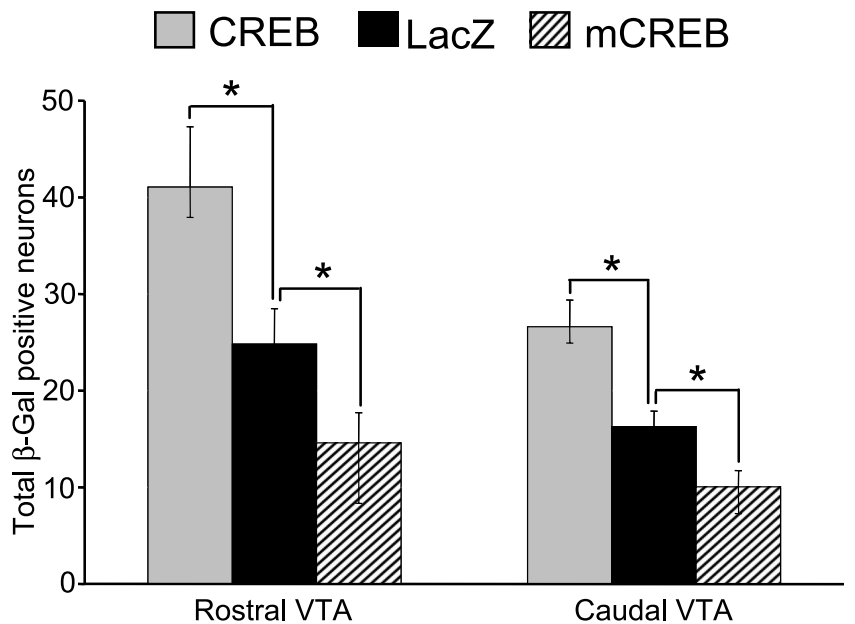

Figure 3. HSV-CREB-GFP and HSV-mCREB-GFP regulate CRE-mediated transcription in the VTA. Animals received injections of HSV-CREB-GFP, HSV-mCREB-GFP, or HSV-Cre-GFP (a control protein) throughout the rostrocaudal axis of the VTA, and sections throughout the VTA were analyzed for CRE-LacZ expression levels. In both rostral and caudal VTA, HSV-CREB-GFP increased, whereas HSV-mCREB-GFP decreased, CRE-LacZ expression levels relative to control animals injected with HSV-Cre-recombinase-GFP. Data are expressed as cell numbers per section \pm SEM $(n=3-4) .{ }^{*} p<0.05 ; t$ test.

different subregions of the VTA (Ikemoto et al., 1997b, 1998; Carlezon et al., 2000; Ikemoto and Wise, 2002; Zangen et al., 2002; Bolanos et al., 2003; Rodd et al., 2005) and with our data demonstrating differential induction of CRE activity within nondopaminergic cells of these subregions in CRE-LacZ mice (Fig. 1). Subsequently, all experimental animals were divided into two groups with injections into either rostral or caudal VTA. As found in several previous studies (Neve and Geller, 1995; Carlezon et al., 1997, 1998, 2000; Neve et al., 1997), injection of HSV vectors caused minimal damage to the infected area, which was indistinguishable from that seen with vehicle injections alone (our unpublished observations).

To confirm the effectiveness of CREB-GFP and mCREB-GFP in regulating CRE-mediated transcription in the VTA in vivo, we injected HSV-CREB-GFP, HSV-mCREB-GFP, or HSV-Cre-GFP throughout the VTA of CRE-LacZ transgenic mice. Expression of CREB-GFP significantly increased CRE-LacZ expression in both rostral and caudal VTA relative to control animals, whereas expression of mCREB-GFP significantly decreased CRE-LacZ expression in both VTA subregions (Fig. 3). These results demonstrate directly that HSV-CREB-GFP and HSV-mCREB-GFP, respectively, appropriately upregulate and downregulate CREmediated transcription, consistent with previous data from our laboratory in other brain regions (Barrot et al., 2002).

\section{Viral-mediated expression of CREB-GFP or mCREB-GFP in} the VTA alters conditioned place preference for morphine We next tested whether altered CREB activity in the VTA also affects the rewarding effects of a threshold dose of morphine. Results equivalent to those seen for cocaine were obtained. Animals that received HSV-CREB-GFP in rostral VTA showed a strong preference for a threshold dose of morphine, whereas those that received HSV-mCREB-GFP into rostral VTA showed a mild aversion. In contrast, animals that received HSV-CREBGFP in caudal VTA showed a mild aversion for this morphine dose, whereas those that received HSV-mCREB-GFP in caudal VTA exhibited strong place conditioning (Fig. 4A). In contrast, injection of the HSV vectors into the nearby substantia nigra had
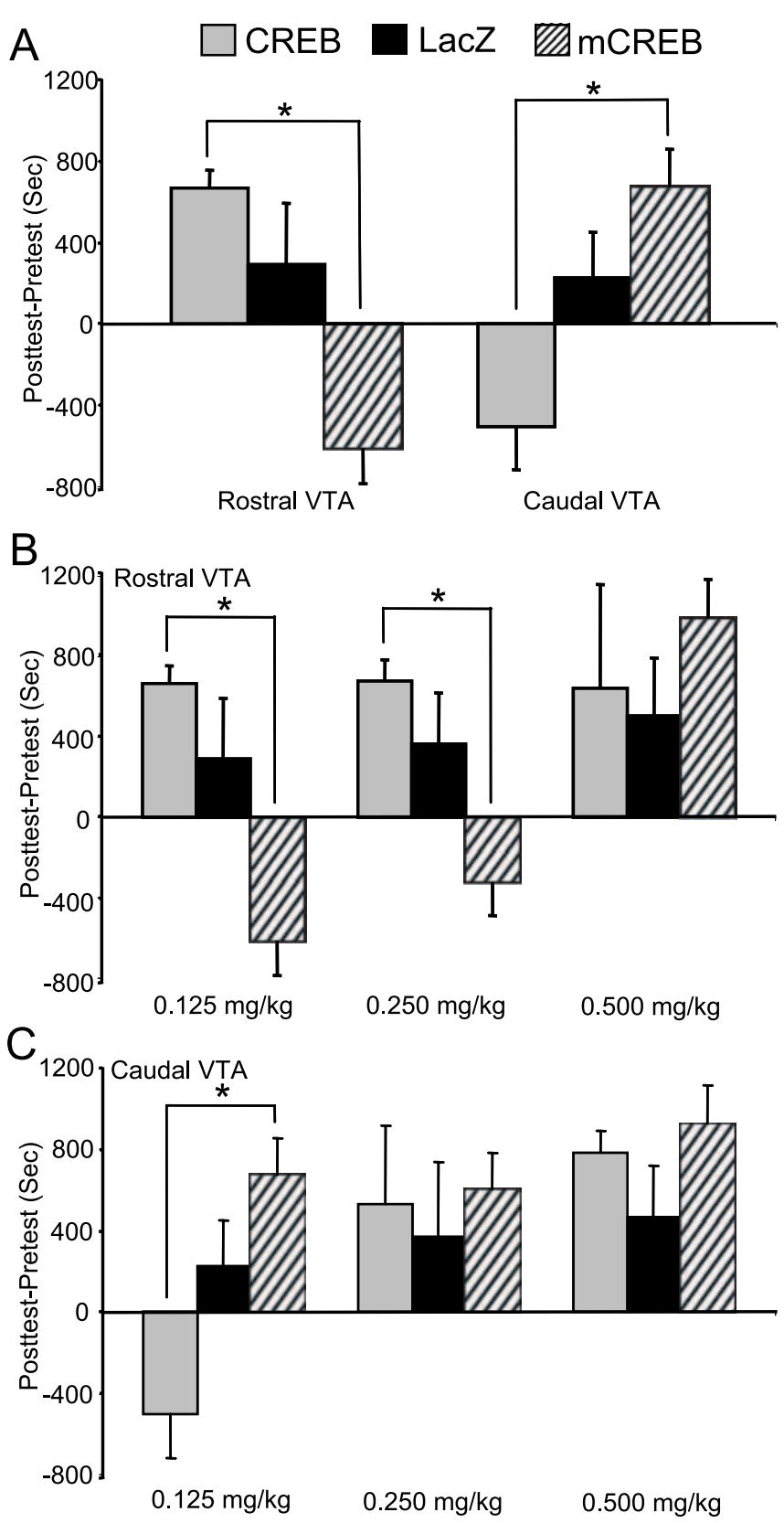

Figure 4. CREB differentially regulates morphine reward in rostral versus caudal VTA. Animals received injections of either HSV-CREB-GFP or HSV-mCREB-GFP throughout the rostrocaudal axis of the VTA and were then trained for conditioned place preference to a threshold dose of morphine $(0.125 \mathrm{mg} / \mathrm{kg}$, s.c.) (A) or a dose range $(0.125,0.25$, or $0.5 \mathrm{mg} / \mathrm{kg}$, s.c.) $(\boldsymbol{B}, \mathbf{C})$. Data reported are mean change in time spent on the drug-paired minus the saline-paired side before and after conditioning ( \pm SEM), which provides a measure of place conditioning. Control animals were injected with HSV-LacZ. Note the opposite effects of CREB and mCREB in the rostral versus caudal VTA $(\boldsymbol{A})$. The effect of $m C R E B$ in rostral VTA $(\boldsymbol{B})$ and the effect of CREB in caudal VTA (C) were overcome by higher doses of morphine. ${ }^{*} p<0.01$; ANOVA and $t$ test $(n=3-8)$.

no effect on morphine reward (data not shown), indicating the regional specificity of CREB action within the VTA.

To better understand these effects of morphine, place conditioning was studied over a full-dose range of the drug. At higher doses of morphine, the effects of HSV-mediated changes in CREB activity in rostral and caudal VTA disappeared, presumably because higher doses of drug overcome the inhibitory effects of HSV-mCREB-GFP in rostral VTA and of HSV-CREB-GFP in caudal VTA. However, a higher dose of morphine $(0.5 \mathrm{mg} / \mathrm{kg})$ 


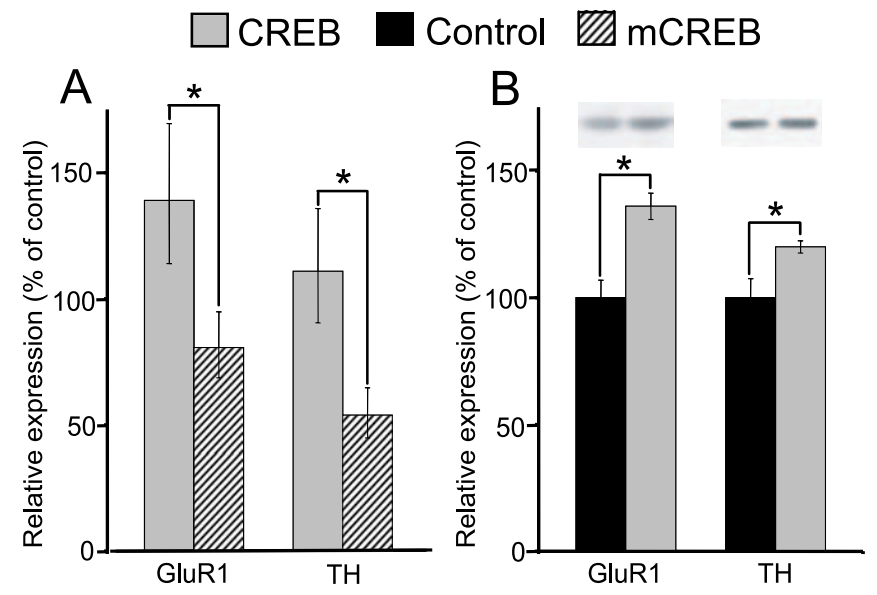

Figure 5. Regulation of GluR1 and TH expression in the VTA by CREB. $A$, GluR1 and TH mRNA expression levels in the VTA of rats injected with HSV-CREB-GFP $(n=11)$ or HSV-mCREB-GFP $(n=12)$ as measured by real-time RT-PCR. Data are displayed as a percentage of expression relative to the control group (HSV-Cre-GFP; $n=13$ ) and are normalized to levels of $\beta$-actin, which is not regulated by these treatments. $\boldsymbol{B}$, GluR1 and TH immunoreactivity in the VTA of rats injected with HSV-CREB-GFP ( $n=7$ ) or HSV-Cre-GFP (control; $n=7$ ) was measured by Western blot analysis and normalized to levels of $\beta$-tubulin, which is not regulated by these treatments. Data are displayed as a percentage of expression in the control group \pm SEM. ${ }^{*} p<0.05$ $t$ test.

was apparently necessary to overcome the effect of HSVmCREB-GFP in rostral VTA compared with HSV-CREB-GFP in caudal VTA $(0.25 \mathrm{mg} / \mathrm{kg})$ (Fig. $4 B, C)$.

GluR1 and TH are putative target genes for CREB in the VTA CREB affects molecular, cellular, and behavioral processes by regulating the transcription of numerous genes. As a first step in understanding the mechanism by which expression of CREBGFP and mCREB-GFP within the VTA alter CPP to drugs of abuse, we used real-time RT-PCR to measure changes in message levels of two CREB-regulated genes implicated in drug reward. Previous studies suggest that both GluR1, an AMPA glutamate receptor subunit that regulates drug reward via its actions in the VTA (Carlezon et al., 1997, 2000; Carlezon and Nestler, 2002), and $\mathrm{TH}$, the rate-limiting enzyme in dopamine biosynthesis induced by drugs of abuse in the VTA (Nestler, 2001), are regulated by CRE sites in their respective promoters (Joh et al., 1978; Lewis et al., 1987; Hiremagalur et al., 1993; Kim et al., 1993; Boundy et al., 1998; Myers et al., 1999; Borges and Dingledine, 2001). We found that expression of CREB-GFP in the VTA increased local GluR1 and TH message levels, whereas expression of mCREBGFP had the opposite effect (Fig. 5A). The relative difference in message levels between CREB-GFP and mCREB-GFP-treated animals was nearly twofold (Fig. 5A). Additional evidence for CREB regulation of these genes was obtained by Western blot analysis. As shown in Figure 5B, injection of HSV-CREB-GFP into the VTA significantly increased levels of TH and GluR1 immunoreactivity in this brain region.

\section{Different neuronal populations are infected in rostral versus caudal VTA}

The VTA is thought to contain two primary types of neurons: dopaminergic neurons, which comprise approximately twothirds of the neurons in this region, and GABAergic neurons, which comprise the remainder. However, the number of dopaminergic neurons is reportedly greater in more caudal subregions of the VTA (Swanson, 1982; German and Manaye, 1993). We therefore hypothesized that our HSV vectors might be infecting different proportions of dopaminergic and GABAergic neurons in caudal VTA versus rostral VTA, and that such differences could contribute to the different behavioral effects observed after vector injections into these subregions. Using double-label immunohistochemistry for GFP (to mark viral infection) and for TH or GAD (a marker of GABAergic neurons), we characterized the types of neurons infected with HSV-CREB-GFP in rostral versus caudal VTA. As shown in Figure $6 \mathrm{~A}$, the percentage of infected neurons colabeled with $\mathrm{TH}$ increased in an approximately linear manner from rostral to caudal VTA. When we examined the number of HSV-infected neurons that expressed $\mathrm{GAD}$, we saw the opposite pattern; the percentage of infected neurons colabeled with GAD decreased in an approximately linear manner from rostral to caudal VTA. Similar results were obtained for HSV-LacZ (data not shown), a control viral vector without behavioral effects, consistent with previous studies demonstrating that efficiency of HSV infection is independent of neuronal type or viral-encoded transgene.

When we pooled the neurons counted into rostral and caudal VTA groups based on the anatomical boundaries used in our behavioral experiments, we found that approximately equal proportions of GABAergic and dopaminergic neurons were infected in rostral VTA. However, in caudal VTA, by far, more infected neurons were dopaminergic than GABAergic (Fig. 6B).

\section{More dopaminergic neurons in caudal VTA project to the NAc than in rostral VTA}

Previous studies have shown that dopamine neurons in the VTA, particularly caudal regions, project to the NAc (Swanson, 1982), a brain region also strongly implicated in drug and natural reward. To determine whether the neurons that we were infecting in caudal VTA project to the NAc, we injected a retrograde tracer (HS) into the NAc shell and HSV-LacZ into both rostral and caudal VTA. We saw no difference in the number of $\beta$-galpositive neurons between rostral and caudal VTA (Fig. 7A). However, consistent with previous studies, we found more retrogradely labeled neurons in caudal than rostral VTA, indicating that more neurons in this subregion project to the NAc. We next examined the projections of these rostral and caudal VTA neurons by colabeling for $\beta$-gal and HS. Of the neurons expressing $\beta$-gal, significantly more neurons in the caudal VTA compared with the rostral VTA were colabeled with HS. Thus, a significantly greater number of infected neurons in caudal VTA than in rostral VTA project to the NAc. In addition, triple labeling for $\beta$-gal, HS, and TH demonstrated that nearly all of these infected projection neurons, in either rostral or caudal VTA, were dopaminergic, a finding consistent with the fact that the majority of VTA projections to the NAc are dopaminergic (Swanson, 1982) (Fig. 7A). These results, combined with those presented above, suggest that the population of HSV transgene-expressing neurons in rostral VTA differs significantly from that in caudal VTA not only in terms of cell type but also in efferent projections.

\section{Discussion}

Using CRE-LacZ reporter mice, we show that CREB activity is upregulated throughout the VTA by chronic morphine administration. We then used viral-mediated expression of CREB-GFP or mCREB-GFP in the VTA to assess the contribution of CREB activity to drug reward. Our study defines two functionally distinct subregions of the VTA (rostral and caudal), which differ dramatically in their responses to CREB-GFP and mCREB-GFP expression. In rostral VTA, CREB-GFP expression made mor- 

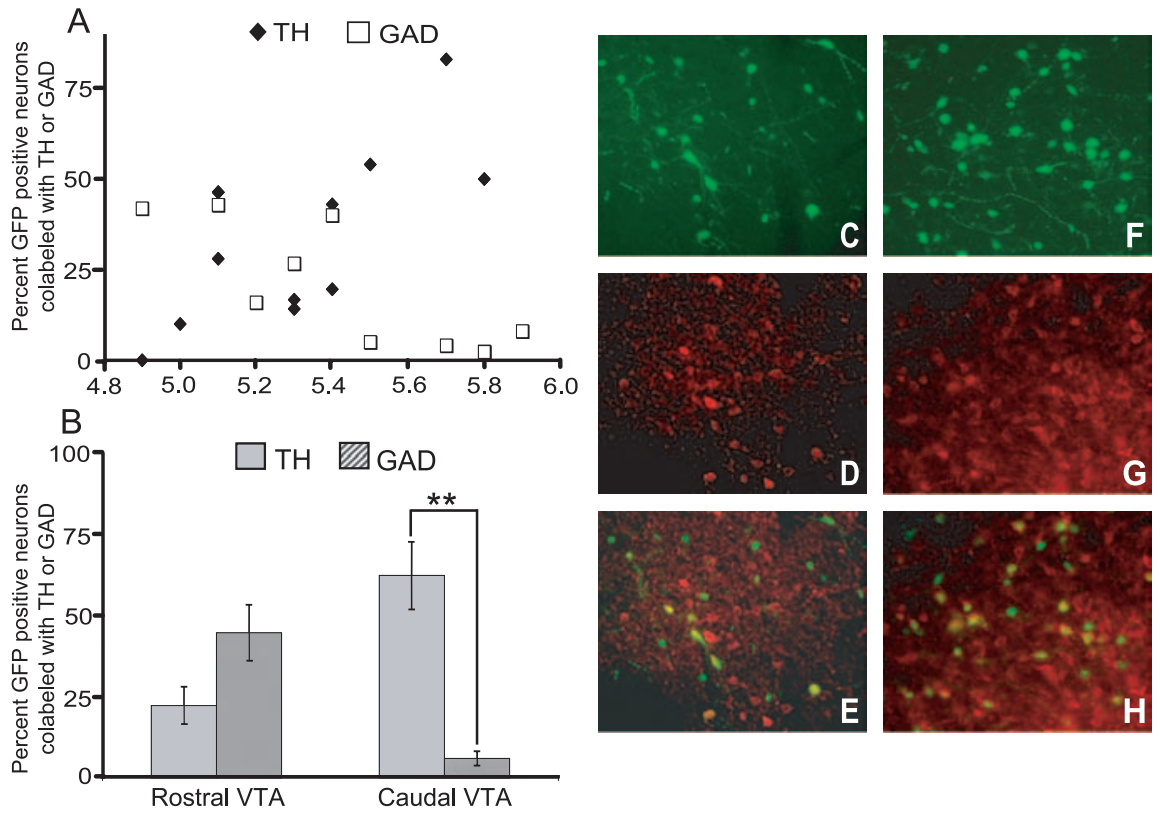

Figure 6. HSV vectors infect different populations of neurons in rostral versus caudal VTA. $\boldsymbol{A}$, Percentage of infected neurons colabeled with TH or GAD varies as a function of bregma coordinates. Data points are taken from sections with a minimum of 20 infected neurons. $\boldsymbol{B}$, In rostral VTA, similar proportions of HSV-infected neurons were colabeled with TH and GAD, respectively. However, in caudal VTA, far more infected neurons were colabeled with TH than GAD $\left({ }^{* *} p<0.001 ; t\right.$ test). C $\boldsymbol{E}$, Representative section taken from an animal injected with HSV-LacZ into rostral VTA, labeled immunohistochemically for $\beta$-gal (C) or GAD (D); a merged image is shown in $\boldsymbol{E}$. $\boldsymbol{F}-\boldsymbol{H}$, Representative section taken from an animal injected with HSV-CREB-GFP injected into caudal VTA, labeled immunohistochemically for GFP $(\boldsymbol{F})$ or TH $(\boldsymbol{G})$; a merged image is shown in $\boldsymbol{H}$.

phine and cocaine more rewarding, whereas mCREB-GFP expression decreased drug reward. Opposite effects were seen in caudal VTA. These findings agree with previous descriptions of two functionally distinct VTA subregions (Arnt and ScheelKruger, 1979; Ikemoto et al., 1997a,b, 1998; Carlezon et al., 2000; Ikemoto and Wise, 2002; Zangen et al., 2002; Bolanos et al., 2003; Rodd et al., 2005). We also identified two target genes for CREB, GluR1 and TH, which could partly mediate the opposing effects of CREB-GFP and mCREB-GFP observed in rostral versus caudal VTA. Finally, our study demonstrates anatomical differences between rostral and caudal VTA that could underlie the functional differences observed in this and previous studies. These subregions differ not only in their responsiveness to drug reward but also in the types of neurons that populate them, as well as in their efferent projections.

Using anatomical boundaries of rostral and caudal VTA described previously, we found that CRE-LacZ expression was increased in rostral and caudal subregions of VTA after chronic drug exposure, consistent with the recent finding that phosphoCREB levels are increased in this region after chronic exposure to drugs of abuse (Walters et al., 2003). CRE-LacZ expression was induced in TH-positive neurons in both VTA subregions, whereas induction in TH-negative neurons, presumably GABAergic, was seen in rostral VTA only. This study is the first to demonstrate that CREB-activated transcription in response to chronic drug administration occurs throughout the VTA, and that this induction occurs in different populations of neurons in rostral versus caudal subregions.

Using viral vectors, we next showed that CREB activation in rostral versus caudal VTA has opposite effects on morphine and cocaine reward. Greater doses of morphine can overcome the effects of CREB-GFP and mCREB-GFP expression in both subregions. This may be a result of the activation of other brain regions involved in morphine reward. Another possibility is that, at higher doses, other transgene-negative VTA neurons are recruited. It is also interesting to note that a higher dose of morphine is required to overcome these effects in rostral rather than caudal VTA. This may reflect the differences in the sensitivity of these two neuronal populations to the effects of either CREB or morphine.

As a transcription factor, CREB produces its effects by regulating the expression of other genes. We examined the expression of two candidate genes that may contribute to CREB action in the VTA: GluR1 and TH. Both genes have functional CREs in their promoters (Lewis et al., 1987; Hiremagalur et al., 1993; Kim et al., 1993; Boundy et al., 1998; Myers et al., 1999; Borges and Dingledine, 2001), and both are upregulated in the VTA by chronic drug exposure (Fitzgerald et al., 1996; Lane-Ladd et al., 1997). Furthermore, upregulation of GluR1 expression, like CREB, has opposite effects on drug reward in rostral versus caudal VTA (Carlezon et al., 2000). Although we were not able to distinguish rostral and caudal VTA in these experiments because of technical limitations (see Materials and Methods), we did find that CREB-GFP expression increases GluR1 and TH mRNA and protein levels in the VTA, and that mCREB-GFP has the opposite effect.

We hypothesized that the functional differences between the effects of CREB in rostral and caudal VTA and similar rostrocaudal differences reported previously may be attributable to neuroanatomical differences between these two subregions. To address this possibility directly, we characterized the relative abundance of two types of VTA neurons, GABAergic and dopaminergic, in rostral and caudal VTA. Whereas approximately equal percentages of GABAergic and dopaminergic neurons were infected in rostral VTA, a much larger percentage of dopaminergic neurons was infected in caudal VTA. Because HSV vectors do not preferentially infect one neuronal cell type more than another, our results presumably reflect the different cellular make up of these two subregions, consistent with previous studies reporting a proportionately greater number of dopamine neurons in caudal VTA (Swanson, 1982; German and Manaye, 1993). In addition, we present evidence that rostral and caudal VTA neurons differ in their efferent projections: many more caudal VTA neurons project to the NAc. Using triple-labeling techniques, we found that, in both rostral and caudal subregions, the large majority of NAc-projecting neurons are dopaminergic. In the present study, retrograde tracer was injected into the mid-rostrocaudal shell of the NAc. Additional studies are needed to determine whether this topographical organization of VTA dopamine projections holds for other NAc subregions.

These rostrocaudal differences in neuronal cell type and projections could explain why the two subregions influence drug reward mechanisms so divergently. The explanation of such differences remains highly speculative, particularly because we do not yet know what effect CREB activity has on the excitability of 
rostral and caudal VTA neurons. Nevertheless, a working hypothesis can be proposed.

Previous studies have shown that expression of GluR1 or administration of picrotoxin, a $\mathrm{GABA}_{\mathrm{A}}$ receptor antagonist, into rostral VTA is rewarding. Both of these treatments could amplify the excitability of rostral VTA neurons either by increasing their sensitivity to glutamate or by disinhibiting them via blockade of $\mathrm{GABA}_{\mathrm{A}}$ receptors. Ikemoto et al. (1997a) suggested that this excitation promotes reward by increasing mesolimbic (i.e., VTA to NAc) dopamine neurotransmission, a hypothesis supported by their finding that administration of picrotoxin into rostral VTA increases dopamine release in the NAc. A similar increase in neuronal activity via CREB-induced GluR1 expression could occur in rostral VTA mesolimbic dopamine neurons. Mesolimbic dopamine release could be further augmented by an increase in TH expression and, consequently, dopamine levels.

Another mechanism that could account for the effects of CREB in rostral VTA is a similar excitation of mesocortical neurons, which predominate in this subregion (Swanson, 1982; Loughlin and Fallon, 1984). Both GABAergic and dopaminergic VTA neurons project to the prefrontal cortex, and activation of both neuronal types inhibits prefrontal cortex neurons (Pirot et al., 1992). This inhibition could lead to decreased corticolimbic excitatory drive, a mechanism proposed to promote reward (Carlezon and Wise, 1996a,b; Wise, 1996, 2002). This hypothesis is supported by our recent finding that injection of HSV vectors into rostral VTA causes transgene expression in mesocortical GABA neurons (V. Olson and E. J. Nestler, unpublished observations), which make up $\sim 70 \%$ of the mesocortical projection (Swanson, 1982). It is also possible that these two mechanisms act synergistically to mediate the effects of CREB in rostral VTA on reward.

Why upregulation of CREB in caudal VTA antagonizes drug reward is less straightforward, but one possible explanation is that elevated CREB levels in this region sensitize an animal to the aversive properties of drugs. Because most neurons in this region are dopaminergic, this effect would appear to be mediated almost exclusively by this cell type. CREB induction of GluR1 and TH in these neurons could increase their excitability and, therefore, local dopaminergic tone. An increase in local dopamine release could activate inhibitory autoreceptors on mesolimbic dopamine neurons (Falkenburger et al., 2001; Beckstead et al., 2004) and could also activate $D_{1}$ receptors on GABA nerve terminals arising from the NAc, increasing local GABA release and further attenuating mesolimbic dopamine neuron firing (Mansour et al., 1991; Sugita et al., 1992; Cameron and Williams, 1993). Such activation of local autoreceptors may also explain why lower, but not higher, doses of cocaine are self-administered into the caudal VTA (Rodd et al., 2005). Moreover, mesocortical dopamine neurons would be impervious to these changes because they do not express inhibitory autoreceptors (Bunney et al., 1973; Aghajanian and Bunney, 1977; Bannon et al., 1981; White and Wang, 1984). A final consideration is that caudal VTA may be a direct target of drugs of abuse, whereas rostral VTA may influence drug reward

through indirect, circuit-level interactions among the major reward regions of the brain. Additional studies are needed to clarify these important issues.

The studies reported here support a fundamental reconsideration of the role of the VTA in brain reward circuitry. Our findings contribute to a growing body of evidence suggesting that the VTA is a heterogeneous brain region, with at least two functionally discrete subregions that can modify drug reward in a distinct and independent manner, neither of which fit the conventional model of drug reward circuitry. We contend that differences in rostral versus caudal VTA, by analogy with differences in the shell versus core subregions of the NAc, should be taken into account in studies of VTA function. We provide two mechanisms for why 
these VTA subregions differ, including a difference in the proportion of dopaminergic versus GABAergic neurons in rostral and caudal VTA, and a difference in the efferent projections of these neurons. Our findings support a distinct role for these VTA subregions in drug reward and provide new insight into the molecular neuropathological changes in this region that contribute to drug addiction.

\section{References}

Aghajanian GK, Bunney BS (1977) Dopamine "autoreceptors": pharmacological characterization by microiontophoretic single cell recording studies. Naunyn Schmiedebergs Arch Pharmacol 297:1-7.

Arnt J, Scheel-Kruger J (1979) GABA in the ventral tegmental area: differential regional effects on locomotion, aggression and food intake after microinjection of GABA agonists and antagonists. Life Sci 25:1351-1360.

Bailey CH, Bartsch D, Kandel ER (1996) Toward a molecular definition of long-term memory storage. Proc Natl Acad Sci USA 93:13445-13452.

Bannon MJ, Michaud RL, Roth RH (1981) Mesocortical dopamine neurons. Lack of autoreceptors modulating dopamine synthesis. Mol Pharmacol 19:270-275.

Barrot M, Olivier JD, Perrotti LI, DiLeone RJ, Berton O, Eisch AJ, Impey S, Storm DR, Neve RL, Yin JC, Zachariou V, Nestler EJ (2002) CREB activity in the nucleus accumbens shell controls gating of behavioral responses to emotional stimuli. Proc Natl Acad Sci USA 99:11435-11440.

Beckstead MJ, Grandy DK, Wickman K, Williams JT (2004) Vesicular dopamine release elicits an inhibitory postsynaptic current in midbrain dopamine neurons. Neuron 42:939-946.

Berhow MT, Hiroi N, Nestler EJ (1996) Regulation of ERK (extracellular signal regulated kinase), part of the neurotrophin signal transduction cascade, in the rat mesolimbic dopamine system by chronic exposure to morphine or cocaine. J Neurosci 16:4707-4715.

Bolanos CA, Perrotti LI, Edwards S, Eisch AJ, Barrot M, Olson VG, Russell DS, Neve RL, Nestler EJ (2003) Phospholipase C $\gamma$ in distinct regions of the ventral tegmental area differentially modulates mood-related behaviors. J Neurosci 23:7569-7576.

Borges K, Dingledine R (2001) Functional organization of the GluR1 glutamate receptor promoter. J Biol Chem 276:25929-25938.

Boundy VA, Gold SJ, Messer CJ, Chen J, Son JH, Joh TH, Nestler EJ (1998) Regulation of tyrosine hydroxylase promoter activity by chronic morphine in TH9.0-LacZ transgenic mice. J Neurosci 18:9989-9995.

Bunney BS, Walters JR, Roth RH, Aghajanian GK (1973) Dopaminergic neurons: effect of antipsychotic drugs and amphetamine on single cell activity. J Pharmacol Exp Ther 185:560-571.

Cameron DL, Williams JT (1993) Dopamine $\mathrm{D}_{1}$ receptors facilitate transmitter release. Nature 366:344-347.

Carlezon Jr WA, Nestler EJ (2002) Elevated levels of GluR1 in the midbrain: a trigger for sensitization to drugs of abuse? Trends Neurosci 25:610-615.

Carlezon Jr WA, Wise RA (1996a) Microinjections of phencyclidine (PCP) and related drugs into nucleus accumbens shell potentiate medial forebrain bundle brain stimulation reward. Psychopharmacology (Berl) 128:413-420.

Carlezon Jr WA, Wise RA (1996b) Rewarding actions of phencyclidine and related drugs in nucleus accumbens shell and frontal cortex. J Neurosci 16:3112-3122.

Carlezon Jr WA, Boundy VA, Haile CN, Lane SB, Kalb RG, Neve RL, Nestler EJ (1997) Sensitization to morphine induced by viral-mediated gene transfer. Science 277:812-814.

Carlezon Jr WA, Thome J, Olson VG, Lane-Ladd SB, Brodkin ES, Hiroi N, Duman RS, Neve RL, Nestler EJ (1998) Regulation of cocaine reward by CREB. Science 282:2272-2275.

Carlezon Jr WA, Haile CN, Coppersmith R, Hayashi Y, Malinow R, Neve RL, Nestler EJ (2000) Distinct sites of opiate reward and aversion within the midbrain identified using a herpes simplex virus vector expressing GluR1. J Neurosci 20:RC62(1-5).

Chao JR, Ni YG, Bolanos CA, Rahman Z, DiLeone RJ, Nestler EJ (2002) Characterization of the mouse adenylyl cyclase type VIII gene promoter: regulation by cAMP and CREB. Eur J Neurosci 16:1284-1294.

Daniel PB, Walker WH, Habener JF (1998) Cyclic AMP signaling and gene regulation. Annu Rev Nutr 18:353-383.

Falkenburger BH, Barstow KL, Mintz IM (2001) Dendrodendritic inhibition through reversal of dopamine transport. Science 293:2465-2470.
Fitzgerald LW, Ortiz J, Hamedani AG, Nestler EJ (1996) Drugs of abuse and stress increase the expression of GluR1 and NMDAR1 glutamate receptor subunits in the rat ventral tegmental area: common adaptations among cross-sensitizing agents. J Neurosci 16:274-282.

German DC, Manaye KF (1993) Midbrain dopaminergic neurons (nuclei A8, A9, and A10): three-dimensional reconstruction in the rat. J Comp Neurol 331:297-309.

Guitart X, Thompson MA, Mirante CK, Greenberg ME, Nestler EJ (1992) Regulation of cyclic AMP response element-binding protein (CREB) phosphorylation by acute and chronic morphine in the rat locus coeruleus. J Neurochem 58:1168-1171.

Hiremagalur B, Nankova B, Nitahara J, Zeman R, Sabban EL (1993) Nicotine increases expression of tyrosine hydroxylase gene. Involvement of protein kinase A-mediated pathway. J Biol Chem 268:23704-23711.

Ikemoto S, Wise RA (2002) Rewarding effects of the cholinergic agents carbachol and neostigmine in the posterior ventral tegmental area. J Neurosci 22:9895-9904.

Ikemoto S, Kohl RR, McBride WJ (1997a) GABA(A) receptor blockade in the anterior ventral tegmental area increases extracellular levels of dopamine in the nucleus accumbens of rats. J Neurochem 69:137-143.

Ikemoto S, Murphy JM, McBride WJ (1997b) Self-infusion of GABA(A) antagonists directly into the ventral tegmental area and adjacent regions. Behav Neurosci 111:369-380.

Ikemoto S, Murphy JM, McBride WJ (1998) Regional differences within the rat ventral tegmental area for muscimol self-infusions. Pharmacol Biochem Behav 61:87-92.

Joh TH, Park DH, Reis DJ (1978) Direct phosphorylation of brain tyrosine hydroxylase by cyclic AMP-dependent protein kinase: mechanism of enzyme activation. Proc Natl Acad Sci USA 75:4744-4748.

Kelz MB, Chen J, Carlezon Jr WA, Whisler K, Gilden L, Beckmann AM, Steffen C, Zhang YJ, Marotti L, Self DW, Tkatch T, Baranauskas G, Surmeier DJ, Neve RL, Duman RS, Picciotto MR, Nestler EJ (1999) Expression of the transcription factor deltaFosB in the brain controls sensitivity to cocaine. Nature 401:272-276.

Kim KS, Lee MK, Carroll J, Joh TH (1993) Both the basal and inducible transcription of the tyrosine hydroxylase gene are dependent upon a cAMP response element. J Biol Chem 268:15689-15695.

Konradi C, Cole RL, Heckers S, Hyman SE (1994) Amphetamine regulates gene expression in rat striatum via transcription factor CREB. J Neurosci 14:5623-5634.

Koob GF, Le Moal M (2001) Drug addiction, dysregulation of reward, and allostasis. Neuropsychopharmacology 24:97-129.

Lane-Ladd SB, Pineda J, Boundy VA, Pfeuffer T, Krupinski J, Aghajanian GK, Nestler EJ (1997) CREB (cAMP response element-binding protein) in the locus coeruleus: biochemical, physiological, and behavioral evidence for a role in opiate dependence. J Neurosci 17:7890-7901.

Lewis EJ, Harrington CA, Chikaraishi DM (1987) Transcriptional regulation of the tyrosine hydroxylase gene by glucocorticoid and cyclic AMP. Proc Natl Acad Sci USA 84:3550-3554.

Loughlin SE, Fallon JH (1984) Substantia nigra and ventral tegmental area projections to cortex: topography and collateralization. Neuroscience 11:425-435.

Mansour A, Meador-Woodruff JH, Zhou QY, Civelli O, Akil H, Watson SJ (1991) A comparison of $\mathrm{D}_{1}$ receptor binding and mRNA in rat brain using receptor autoradiographic and in situ hybridization techniques. Neuroscience 45:359-371.

Mayr B, Montminy M (2001) Transcriptional regulation by the phosphorylation-dependent factor CREB. Nat Rev Mol Cell Biol 2:599-609.

McBride WJ, Murphy JM, Ikemoto S (1999) Localization of brain reinforcement mechanisms: intracranial self-administration and intracranial place-conditioning studies. Behav Brain Res 101:129-152.

Myers SJ, Dingledine R, Borges K (1999) Genetic regulation of glutamate receptor ion channels. Annu Rev Pharmacol Toxicol 39:221-241.

Nestler EJ (2001) Molecular basis of long-term plasticity underlying addiction. Nat Rev Neurosci 2:119-128.

Neve RL, Geller AI (1995) A defective herpes simplex virus vector system for gene delivery into the brain: comparison with alternative gene delivery systems and usefulness for gene therapy. Clin Neurosci 3:262-267.

Neve RL, Howe JR, Hong S, Kalb RG (1997) Introduction of the glutamate receptor subunit 1 into motor neurons in vitro and in vivo using a recombinant herpes simplex virus. Neuroscience 79:435-447. 
Ortiz J, Fitzgerald LW, Charlton M, Lane S, Trevisan L, Guitart X, Shoemaker W, Duman RS, Nestler EJ (1995) Biochemical actions of chronic ethanol exposure in the mesolimbic dopamine system. Synapse 21:289-298.

Paxinos G (1995) The rat nervous system, Ed 2, p 218. New York: Elsevier.

Perkinton MS, Sihra TS, Williams RJ (1999) $\mathrm{Ca}^{2+}$-permeable AMPA receptors induce phosphorylation of cAMP response element-binding protein through a phosphatidylinositol 3-kinase-dependent stimulation of the mitogen-activated protein kinase signaling cascade in neurons. J Neurosci 19:5861-5874.

Pirot S, Godbout R, Mantz J, Tassin JP, Glowinski J, Thierry AM (1992) Inhibitory effects of ventral tegmental area stimulation on the activity of prefrontal cortical neurons: evidence for the involvement of both dopaminergic and GABAergic components. Neuroscience 49:857-865.

Rajadhyaksha A, Barczak A, Macias W, Leveque JC, Lewis SE, Konradi C (1999) L-type $\mathrm{Ca}^{2+}$ channels are essential for glutamate-mediated CREB phosphorylation and c-fos gene expression in striatal neurons. J Neurosci 19:6348-6359.

Riccio A, Ginty DD (2002) What a privilege to reside at the synapse: NMDA receptor signaling to CREB. Nat Neurosci 5:389-390.

Rodd ZA, Bell RL, Kuc KA, Zhang Y, Murphy JM, McBride WJ (2005) Intracranial self-administration of cocaine within the posterior ventral tegmental area of Wistar rats: evidence for involvement of serotonin-3 receptors and dopamine neurons. J Pharmacol Exp Ther 313:134-145.

Shaw-Lutchman TZ, Barrot M, Wallace T, Gilden L, Zachariou V, Impey S, Duman RS, Storm D, Nestler EJ (2002) Regional and cellular mapping of cAMP response element-mediated transcription during naltrexoneprecipitated morphine withdrawal. J Neurosci 22:3663-3672.

Shaw-Lutchman TZ, Impey S, Storm D, Nestler EJ (2003) Regulation of
CRE-mediated transcription in mouse brain by amphetamine. Synapse 48:10-17.

Shaywitz AJ, Greenberg ME (1999) CREB: a stimulus-induced transcription factor activated by a diverse array of extracellular signals. Annu Rev Biochem 68:821-861.

Sugita S, Johnson SW, North RA (1992) Synaptic inputs to GABA and $\mathrm{GABA}_{\mathrm{B}}$ receptors originate from discrete afferent neurons. Neurosci Lett 134:207-211.

Swanson LW (1982) The projections of the ventral tegmental area and adjacent regions: a combined fluorescent retrograde tracer and immunofluorescence study in the rat. Brain Res Bull 9:321-353.

Walters CL, Kuo YC, Blendy JA (2003) Differential distribution of CREB in the mesolimbic dopamine reward pathway. J Neurochem 87:1237-1244.

White FJ, Wang RY (1984) A10 dopamine neurons: role of autoreceptors in determining firing rate and sensitivity to dopamine agonists. Life Sci 34:1161-1170.

Wise RA (1996) Neurobiology of addiction. Curr Opin Neurobiol 6:243-251.

Wise RA (2002) Brain reward circuitry: insights from unsensed incentives Neuron 36:229-240.

Wolf DH, Numan S, Nestler EJ, Russell DS (1999) Regulation of phospholipase $\mathrm{C} \gamma$ in the mesolimbic dopamine system by chronic morphine administration. J Neurochem 73:1520-1528.

Wolf ME (2003) Effects of psychomotor stimulants on glutamate receptor expression. Methods Mol Med 79:13-31.

Zangen A, Ikemoto S, Zadina JE, Wise RA (2002) Rewarding and psy chomotor stimulant effects of endomorphin-1: anteroposterior differences within the ventral tegmental area and lack of effect in nucleus accumbens. J Neurosci 22:7225-7233. 